\title{
THE EC Biomedical and health research programme BIOMED (1991-1994)
}

\section{Rationale and objectives}

BIOMED 1 is a specific programme under the Third Framework Programme (1990-1994). Its objectives are "to contribute to improving the efficacy of medical and health research and development in the Member States, in particular by better coordination of the Member States' research and development activities and application of the results through Community cooperation and a pooling of resources" and to encourage "basic research in the field of biomedicine and health throughout the Community".

\section{Technical Areas - Research Topics}

BIOMED 1 is divided into four areas:

Area 1: development of coordinated research on prevention, care and health systems

This area covers the harmonisation of methodologies and protocols in epidemiological, biological, clinical and technological research.

The key targets will be:

\section{(a) Drugs and the administration of medicines}

Precompetitive drug testing with a view to improved harmonisation of norms and parameters, and research into the monitoring and surveillance of drug prescribing practices, patient compliance and the incidence of adverse drug reactions;

\section{(b) Risk factors and occupational medicine}

Research into risk factors, especially in the context of occupational medicine, with a view to the identification of potential risk factors and the early prevention of disease;

\section{(c) Biomedical technology}

Enhancement and application of biomedical instruments and devices for medical and health care, directed towards the development of coherent systems and procedures for diagnosis, therapy, prevention, care and rehabilitation;

\section{(d) Health services research}

Harmonisation of protocols and approaches in health services, particularly with the completion of the internal market in view, and research into the financing of health care, the management of the health care workforce, and health care systems; the methodology of research into prevention, therapy and rehabilitation will also be studied.

Area 2: major health problems and diseases of great socio-economic impact

Major health problems and economically and socially significant disease groupings will be considered, in particular the following: 


\section{(a) AIDS}

Disease prevention; basic research; clinical research; the development of a European vaccine against AIDS; trials of antiviral drugs in AIDS management.

\section{(b) Cancer}

Epidemiology and basic research on genomic and phenotypic changes in cancer cells (invasion and metastasis); immune surveillance; coordination of research work on oncogenes and antioncogenes; improvement of European tumour cell and tissue bank resources; development of a scientific basis for guidelines for anti-cancer drug screening.

\section{(c) Cardiovascular disease}

The various forms of heart and circulatory disease, including correlation between genetic factors, lifestyle, nutrition, and the incidence and development of cardiovascular disturbances; effects of prophylactic and therapeutic measures; development of new regimes for treatment, including non-invasive methods of diagnosis; testing of drugs.

\section{(d) Mentail illness and neurological disease}

The study of aetiological and predisposing conditions; studies to improve understanding of the causes of mental illness and also of the evolution from pathology to disability and social disadvantage; development of new methods of prevention and care; studies in enzymology, neuroendocrinol- ogy and genetics; psychosocial phenomena during the development of diseases such as cancer, AIDS or cardiovascular disorders.

(e) The ageing process, and age-related health problems and handicaps

Comparative research on perinatal illnesses and paediatric illnesses, and on the effectiveness of prophylactic and therapeutic measures; the maintenance of the quality of life in the aged; ageing in different social settings; specific pathologies relating to ageing; relaltionship between dysfunction, decrease in functional capacity and resulting disabilities; methods of improving organ transplants; effects of the environment on health, especially on people in more vulnerable age groups.

\section{Area 3: human genome analysis}

Research aimed at the completion and the integration of the genetic and physical maps; study of the genetic basis for biological functions; settingup of a coordinating mechanism to sequence portions of the genome of major biological interest; attempts to understand the genetic component of multifactorial conditions such as Alzheimer's disease, and to develop methods intended to improve treatment.

Links will be maintained with appropriate internatinal organisations or fora (e.g. HUGO, the Human Genome Organisation), as well as with

\begin{tabular}{|c|c|}
\hline \multicolumn{2}{|l|}{ INDICATIVE TIMETABLE } \\
\hline$\overline{\text { ACTIVITY }}$ & DATE \\
\hline INFORMATION PACKAGE AVAILABLE & December 1992 \\
\hline START SECOND CALL FOR PROPOSALS & December 1992 \\
\hline $\begin{array}{l}\text { DEADLINE FOR RECEIPT OF PROPOSALS } \\
\text { - Area } 3 \text { (Human and Genome Analysis) } \\
\text { - Areas 1,2 and } 4\end{array}$ & $\begin{array}{l}29 \text { January } 1993 \\
\text { 26 February } 1993\end{array}$ \\
\hline $\begin{array}{l}\text { EVALUATION OF PROPOSALS } \\
\quad \text { - Area } 3 \\
\text { - Areas } 1,2 \text { and } 4\end{array}$ & $\begin{array}{l}\text { February to April } 1993 \\
\text { March to June } 1993\end{array}$ \\
\hline $\begin{array}{l}\text { IMPLEMENTATION } \\
\quad \text { - Area } 3 \\
\quad \text { - Areas } 1,2 \text { and } 4\end{array}$ & $\begin{array}{l}\text { May } 1993 \text { onwards } \\
\text { July } 1993 \text { onwards }\end{array}$ \\
\hline
\end{tabular}


research activities in non-Member States using similar or complementary approaches.

\section{Area 4: research on biomedical ethics}

This area will involve problems relating to the research carried out in areas 1 to 3 of the programme; it may also be linked to the possible applications of the research results.

Work will deal with the evaluation of questions of biomedical ethics linked with the BIOMED programme, the evaluation of the social impact of the programme and the risks (including the technological risks) which might be associated with it.

\section{Background}

The involvement of the European Community in the field of Medical and Health research started in 1978 with a first Programme. Since then, it has steadily expanded from three research networks to a likely total of around 250 at the end of the current fifth programme (1994).

Its basis is the coordination of national research activities, the cost of which must be met from national sources but with the European Community meeting the further costs of working on an international basis.

The aim is to achieve a critical mass of interested researchers by bringing together their cumulative expertise to find solutions to medical and health problems of major importance for Europe, which can best be solved by working at the European level rather than only in individual Member States, i.e. by applying the principle of subsidiarity. A common protocol or a set of harmonized protocols needs to be used, so that valid conclusions can be drawn in due course from data obtained by teams from all the different countries.

\section{Implementation}

Funds are provided by the Community for relevant "concerted actions" (CAs) which consist of research collaboration and coordination in EC Member States and also in other European participant countries. The approved uses of CA funds can include the organization of meetings; scientific and administrative support; short-term international exchanges of personnel; preparation and distribution of materials and reference products; centralized data handling, storage and statistical analysis; and dissemination of information and results. In addition a "centralized facility" can be provided to ensure appropriate European resources or services if it is necessary for one or more CAs to have access to particular quality control products, experimental materials or specialized services, or if there are some other reference-type needs. One part of the programme functions through "shared-cost actions" with the EC normally meeting $50 \%$ of the cost of the research; this part is Area 3, human genome analysis. In addition fellowships can be awarded in all subjects covered by the programme.

\section{Biomedical Technology}

Projects selected after the 1992 call for proposals: Laser-Doppler flowmetry for microcirculation monitoring

K. Möller (D)

Heart assist and replacement

B. Mambrito (I)

Conception, elaboration and development of an original osteoinductive biocomposite material for bone substitution

M. Rabaud (F)

Development and harmonization of the norms and parameters in biological testing protocols designed for root canal sealers in the European community

\section{A. Watts (UK)}

European standardized computerized assessment procedure for the evaluation and rehabilitation of brain-damaged patients (E.S.C.A.P.E.)

G. Deloche (F)

Study of variable transition zones in an attempt to use excimer lasers in photo-refractive keratectomy for addressing high myopia

I. Pallikaris (GR)

Restoration of muscle activity through fes and associated technology (RAFT)

A. Pedotti (I) 
Cancer and brain disease characterization and therapy assessment by quantitative magnetic resonance spectroscopy

F. Podo (I)

Positron emission tomograpy of cellular regeneration and degeneration

D. Comar (B)

Electrical impedance tomography

D. Barber (UK)

Automated molecular cytogenetic analysis

A. Raap (NL)

Pharmacologic stress echocardiography: a new, effective and inexpensive method for non-invasive diagnosis of coronary disease in clinical cardiology A. Distante (I)

Assessment of quality of bone in osteoporosis

J. Dequeker (B)

Chemical sensors for in vivo monitoring

A. Turner (UK)

Ocular fluorometry - euroeye. New methods and instrumentation for non-invasive diagnosis by ocular fluorescence measurement

E. Leite (P)

Otoacoustic emissions

F. Grandori (I)

Near infrared spectroscopy and imaging for noninvasive monitoring of the oxygenation and haemodynamic status of tissues

P. Rolfe (UK)

\section{Where to obtain more information?}

Dr. Viviane Thévenin

Commission of the EC - DG XII-F-6

SDME 2/50

rue de la Loi 200

1049 Bruxelles

Tel: + 3222950034

Fax: + 3222955365 